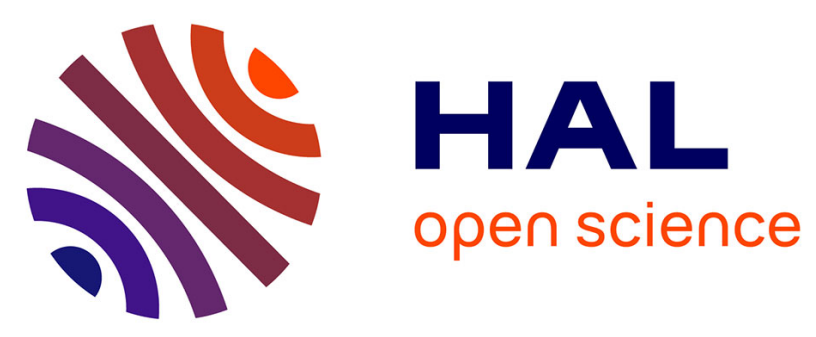

\title{
Ventilatory Parameters and Maximal Respiratory Pressure Changes With Age in Duchenne Muscular Dystrophy Patients
}

Jérome Gayraud, Michèle Ramonatxo, Francois Rivier, Véronique Humberclaude, Basil Petrof, Stefan Matecki

\section{To cite this version:}

Jérome Gayraud, Michèle Ramonatxo, Francois Rivier, Véronique Humberclaude, Basil Petrof, et al.. Ventilatory Parameters and Maximal Respiratory Pressure Changes With Age in Duchenne Muscular Dystrophy Patients. Pediatric Pulmonology, 2010, 45 (6), pp.552-559. 10.1002/ppul.21204 . hal02546591

\section{HAL Id: hal-02546591 \\ https://hal.umontpellier.fr/hal-02546591}

Submitted on 18 Apr 2020

HAL is a multi-disciplinary open access archive for the deposit and dissemination of scientific research documents, whether they are published or not. The documents may come from teaching and research institutions in France or abroad, or from public or private research centers.
L'archive ouverte pluridisciplinaire HAL, est destinée au dépôt et à la diffusion de documents scientifiques de niveau recherche, publiés ou non, émanant des établissements d'enseignement et de recherche français ou étrangers, des laboratoires publics ou privés. 


\title{
Ventilatory Parameters and Maximal Respiratory Pressure Changes With Age in Duchenne Muscular Dystrophy Patients
}

\author{
Jerome Gayraud, MD, ${ }^{1,2}$ Michele Ramonatxo, PhD, ${ }^{1,2,3}$ François Rivier, MD, PhD, ${ }^{1,2,4}$ \\ Véronique Humberclaude, $\mathrm{MD}^{2,5,6}$ Basil Petrof, ${ }^{\mathrm{MD}}{ }^{7}$ and Stefan Matecki, MD, $\mathrm{PhD}^{1,2,3 *}$
}

\begin{abstract}
Summary. The aim of this longitudinal study was to precise, in children with Duchenne muscular dystrophy, the respective functional interest of ventilatory parameters (Vital capacity, total lung capacity and forced expiratory volume in one second $\left[\mathrm{FEV}_{1}\right]$ ) in comparison to maximal inspiratory pressure (Pimax) during growth. In ten boys the mean age of $9.1 \pm 1$ years) to mean age of $16 \pm 1.4$ years followed over a period of 7 years, we found that: (1) ventilatory parameters expressed in percentage of predicted value, after a normal ascending phase, start to decrease between 11 and 12 years, (2) Pimax presented only a decreasing phase since the beginning of the study and thus was already at $67 \%$ of predicted value at 12 years while ventilatory parameters was still normal, (3) after 12 years the mean slopes of decrease per year of vital capacity and FEV1 were higher (10.7 and $10.4 \%$ ) than that of Pimax (6.9\%), (4) at 15 years mean values of vital capacity and FEV1 (53.3 and $49.5 \%$ of predicted values) was simlar to that of Pimax (48.3\%). In conclusion, if at early stages of the disease, Pimax is a more reliable index of respiratory impaiment than ventilatory parameters, the follow-up of ventilatory parameters, when they start to decrease, is a better indicator of disease progression and, at advanced stages they provided same information about the functional impact of disease.
\end{abstract}

Key words: Duchenne muscular dystrophy; maximal inspiratory pressure; pulmonary function; longitudinal study.

\section{INTRODUCTION}

Duchenne muscular dystrophy (DMD), an X-linked recessive disorder caused by absence or severely reduced expression of dystrophin, ${ }^{1}$ is characterized by progressive degeneration of skeletal muscles, including the respiratory muscles. ${ }^{2}$ Unfortunately, despite advances in respiratory support, death generally occurs at 25-30 years of age, due to respiratory failure in more than $80 \%$ of cases. ${ }^{3}$ Many studies have evaluated respiratory function in patients with DMD and described a pattern of restrictive ventilatory impairment. ${ }^{2,4-8}$ More specifically, pulmonary volumes show a characteristic pattern consisting of an initial ascending phase associated with age-related growth, followed by a plateau and finally a descending phase. ${ }^{5,6}$ Since a correlation has been found between pulmonary volumes and DMD disease stages, ${ }^{4}$ the followup of respiratory function is important for prognosis. Indeed, the extent of the plateau phase and the rate of the declining phase of vital capacity correlates with the risk of respiratory failure as well as life expectancy., ${ }^{2,5,9}$ Moreover, the fall of vital capacity to a value below one liter points to an elevated likelihood of death within the following 3 years if mechanical ventilatory support is not provided. ${ }^{9}$ Nevertheless, spirometry does not seem to be a sensitive indicator of respiratory muscle weakness during
${ }^{1}$ Inserm, ERI25, Montpellier F-34295, France.

${ }^{2}$ University Montpellier1, UFR Medicine, EA 4202, Montpellier F-34295, France.

${ }^{3}$ CHU Montpellier, Hôpital A de Villeneuve, Service de Physiologie Clinique, Montpellier F-34295, France.

${ }^{4} \mathrm{CHU}$ Montpellier, Hôpital Saint-Eloi, Service de Neuropédiatrie, Montpellier, France.

${ }^{5}$ Inserm, U827, Montpellier, France.

${ }^{6}$ Laboratory of Molecular Genetic, Hôpital A de Villeneuve, Montpellier, France.

${ }^{7}$ Meakins-Christie Laboratories, McGill University, Montreal, QC, Canada Jerome Gayraud and Michele Ramonatxo contributed equally to this work

*Correspondence to: Stefan Matecki, MD, PhD, CHU Montpellier, Hôpital A de Villeneuve, Service de Physiologie Clinique, Montpellier F-34295, France. E-mail: s-matecki@chu-montpellier.fr 
earlier stages of the disease. In this regard, vital capacity usually remains normal or near-normal until there is a major decline (to about 50\% predicted) in respiratory muscle strength. ${ }^{10}$

Since skeletal muscle weakness is the main physiological consequence of dystrophin defects in DMD, respiratory muscle function has been proposed as a potential index of disease progression. Although not sensitive to early changes as noted above, the decrease of vital capacity over time in DMD patients correlates with reductions in maximal inspiratory pressure (Pimax), which in turn reflect inspiratory muscle strength. ${ }^{11}$ Indeed, respiratory muscle weakness is the first sign of dysfunction of the respiratory system at early stages of the disease, ${ }^{11,12}$ and hypercapnia will not appear until Pimax is less than $30 \%$ of the normal predicted value. ${ }^{13}$ In addition, with age, respiratory muscle weakness is often associated with superimposed alterations of respiratory system mechanical properties in DMD children. ${ }^{13}$ The variability and the difficulties of performing Pimax measurements caused by the cognitive impairment which is often present in DMD children ${ }^{14}$ may also alter the usefulness of respiratory muscle function as a parameter for following disease progression.

Accordingly, the primary aim of this longitudinal study was to perform a systematic comparison of commonly used ventilatory parameters and Pimax during the longterm follow-up of DMD children, in order to determine which is most reflective of disease progression with increasing age. To achieve this goal, we followed 10 DMD boys for an average period of 7 years, spanning mean ages of $9 \pm 1$ years until $16.0 \pm 1.4$ years old.

\section{PATIENTS AND METHODS}

\section{Patients}

Ten male children and adolescents with DMD from a mean age of $9 \pm 1$ years to a mean age of $16.0 \pm 1.4$ years (followed on average over a period of 7 years) participated in this longitudinal study. They belonged to a group of patients with neuromuscular diseases followed at the Department of Neuropediatrics of the St. Eloi University Hospital Center in Montpellier and the Saint-Pierre Institute in Palavas, France, and were referred to our pulmonary function laboratory for routine respiratory evaluation.

Inclusion criteria were: (1) confirmed diagnosis of DMD clinically and by muscle biopsy (demonstration of absence of dystrophin expression, except for occasional muscle fibers, by immunohistochemistry), (2) absence of any requirement for assisted ventilation, (3) clinical stability without any symptoms or signs of inspiratory muscle insufficiency, such as orthopnea, paradoxical breathing or hypercapnia, (4) absence of major learning disabilities and ability to perform the maneuvers recommended by the American Thoracic Society/European
Respiratory Society for lung volume measurements, ${ }^{15}$ and (5) available measurements of ventilatory parameters and Pimax for a period of at least 5 years. Exclusion criteria were: (1) presence of respiratory tract infection or history of acute respiratory failure requiring endotracheal ventilation and (2) presence of medications that could influence respiratory function ${ }^{16}$ during the time of the study, including the use of corticosteroids. Four patients had independent ambulation at the first evaluation, but none of the subjects could walk after the age of 12 . Among the 10 patients, one received spinal arthrodesis at 12 years of age, and two received this intervention at 16 years of age near the end of their study evaluations. Since a recently validated scale for motor function assessment ${ }^{17}$ was not yet available at the beginning of this study, we evaluated daytime activities according to a score which was routinely used by our clinical service. This score contains three main items: (a) ability to stand up and transfer weights with and without support (score ranges from 0 to 45), (b) capacity to get dressed (score ranges from 0 to 45), and (c) capacity to eat (score ranges from 0 to 30 ). The total score ranges from 0 to 120 . We also evaluated their intellectual quotient (IQ) with the Wechler's scale (N.PPSI, WISC.R, WISC III) according to the age and period of investigation, as well as their verbal and performance intellectual quotients (V.IQ and P.IQ).

\section{Physiological Measurements}

\section{Handgrip Strength}

To measure handgrip strength, trials of maximal voluntary isometric contraction of one hand were performed with a Saefran dynamometer (MAFEZ, 630-728, Korea) until we obtained three reproducible measurements. Unfortunately, the longitudinal follow-up of this measure was not possible for all children; therefore, we only report the values obtained at the age of 13 years (Table 1), which also represents the mean age at which peak values obtained for the vital capacity and forced expiratory volume in $1 \mathrm{sec}\left(\mathrm{FEV}_{1}\right)$.

\section{Ventilatory Parameters}

As part of their routine clinical care, eight patients were evaluated at least twice per year and two only once, from November 1993 to January 2005. The FEV 1 and vital capacity were determined by spirometry (Pulmonet III; sensor Medics, Anaheim, CA) according to standard techniques and procedures, while the children were seated in their own wheelchairs. We assessed the functional residual capacity using the helium dilution technique. We expressed vital capacity, total lung capacity and $\mathrm{FEV}_{1}$ in absolute values as well as percentages of predicted values according to Zapletal et al. ${ }^{18}$ For this, the height of each 
TABLE 1-Known Mutations, Score of Daytime Activity, and Dominant Handgrip Value for All Children at the Age of 12-13 Years

\begin{tabular}{rlrc}
\hline & \multicolumn{1}{c}{ Known mutations localization } & $\begin{array}{c}\text { Score of daytime } \\
\text { activity }\end{array}$ & $\begin{array}{c}\text { Dominant handgrip } \\
\text { (kg force) }\end{array}$ \\
\hline 1 & c.10086+1G>(IVS69+1G $>\mathrm{T})$ & $65 / 120$ & 3.5 \\
2 & c.32_93+dup (ex2dup) & $50 / 120$ & 3.0 \\
3 & c.9568>T(p.Arg31190X) & $17 / 120$ & 1.5 \\
4 & c.32-?_dup(exdup) & $36 / 120$ & 5.7 \\
5 & Stand-by & $69 / 120$ & 13.0 \\
6 & c.7310-?7542+?del(ex51del) & $86 / 120$ & 3.0 \\
7 & c.7201-?_7309+del(ex50del) & $32 / 120$ & 2.0 \\
8 & c.8548-?_9224+?dup(ex58ex62dup) & $34 / 120$ & 2.0 \\
9 & Stand-by & $27 / 120$ & 0.1 \\
\hline
\end{tabular}

child was evaluated in a lying position with a rope and measured on a scale.

\section{Maximal Inspiratory Pressure (Pimax)}

The same pediatrician supervised all Pimax measurements during the patients' follow-up as previously done in our laboratory. ${ }^{19,20}$ Children breathed through a plastic cylinder connected to a mouthpiece. Pimax was measured at the functional residual capacity with a Validyne MP45 transducer $\left( \pm 300 \mathrm{cmH}_{2} \mathrm{O}\right)$ and a CD 15 carrier demodulator using the technique described by Black and Hyatt. ${ }^{10}$ The method has been described in a previous study. ${ }^{20}$ To prevent generation of pressure in the buccal cavity by the cheeks against a closed glottis, a small air leak was created by a needle ( $28 \mathrm{~mm}$ length, $1.2 \mathrm{~mm}$ internal diameter). In order to motivate the subjects to produce a maximal inspiratory effort, we allowed them to observe the values of their inspiratory pressure measurements on a screen during the test. After each measurement, the pediatrician traced a horizontal line on the screen and encouraged the child to exceed his last value. We retained only plateau pressure values that could be sustained for more than $1 \mathrm{sec}$. The examiner carried out at least five measurements to obtain three reproducible values (i.e., variation in maximal inspiratory pressure $<10 \%$ ). We selected the Pimax highest value, expressed for each subject in absolute terms and as a percentage of predicted at the same lung volume.

\section{Protocol}

First, we assessed the ventilatory parameters (i.e., functional residual capacity, total lung capacity, vital capacity and $\mathrm{FEV}_{1}$ ) at rest, while the child was sitting on his own wheelchair in a calm and relaxed condition. Then, we connected the child to the previously described respiratory apparatus to measure Pimax. During the measurements, we took great care to ensure that each child sat on his chair in the same position with relaxed shoulders.

\section{Statistical Analysis}

We expressed all values as means \pm standard error of the mean (SEM). We used linear regression equations to analyze the decrease of the ventilatory parameters with age as well as Pearson's correlation coefficient. We assessed the differences between ventilatory parameters and Pimax values using Student's $t$-test when the normality distribution (Kolomogorov-Smirnov test) and equality of variance (Levine median test) were verified. The level of significance was set at $P<0.05$.

\section{RESULTS}

\section{Patients}

Table 1 shows the known mutations, daytime activity scores and dominant handgrip strength values at the age of 12-13 years. We described the mutations according to the coding DNA reference sequence of the Dp427m isoform (Genbank file NM_004006.1) and to the most recent recommendations of the Human Genome Variation Society. At this age, and similarly to a previous study, ${ }^{16}$ we found a significant correlation between dominant handgrip strength and daytime activity score $(\mathrm{Y}=0.17 \mathrm{X}-2.62, \mathrm{r}=0.88, P<0.01)$, but not between daytime activity score and ventilatory parameters or maximal inspiratory pressure. We also did not find any correlation between handgrip strength and ventilatory parameters or maximal inspiratory pressure. Indeed, all children were wheelchair-bound at this age and thus presented a low level of ventilatory demand, such that respiratory muscle function did not appear to be a limiting factor for their usual daytime activities.

Table 2 presents the relevant clinical and functional information for individual patients such as the age at which subjects stopped walking, the age of first recording, the duration of follow-up, baseline height and weight data, and baseline ventilatory parameters. In this study, we assessed ventilatory parameters and maximal inspiratory pressure over an average follow-up period of 
TABLE 2-Individual Relevant Clinical and Functional Information: Age Subject Stopped Walking, Age of the Firs Recording, Duration of Follow-Up, Baseline Height, Weight and Body Mass Index, Baseline Value of Forced Vital Capacity (FVC), Forced Expiratory Volume in $1 \mathrm{sec}$ (FEV1) and Total Lung Capacity (TLC)

\begin{tabular}{|c|c|c|c|c|c|c|c|c|c|}
\hline $\begin{array}{l}\text { Patient } \\
\text { number }\end{array}$ & $\begin{array}{c}\text { Stopped walking } \\
\text { (years) }\end{array}$ & $\begin{array}{l}\text { Firs recording } \\
\text { (years) }\end{array}$ & $\begin{array}{l}\text { Follow-up } \\
\text { (years) }\end{array}$ & $\begin{array}{l}\text { Baseline height } \\
(\mathrm{cm})\end{array}$ & $\begin{array}{c}\text { Baseline } \\
\text { weight }(\mathrm{kg})\end{array}$ & $\begin{array}{l}\text { Body mass } \\
\text { index }\end{array}$ & $\mathrm{FVC}(\mathrm{L})$ & FEV1 (L) & TLC (L) \\
\hline 1 & 12 & 7 & 6 & 126 & 24 & 15 & 1.13 & 0.76 & 1.95 \\
\hline 2 & 9 & 11 & 7 & 143 & 45 & 22 & 2.23 & 1.96 & 2.82 \\
\hline 3 & 9 & 10 & 7 & 135 & 43 & 24 & 1.48 & 1.10 & 2.83 \\
\hline 4 & 9 & 9 & 7 & 133 & 37 & 21 & 1.88 & 1.82 & 2.14 \\
\hline 5 & 10 & 8.5 & 8 & 125 & 23 & 15 & 1.63 & 1.40 & 2.28 \\
\hline 6 & 11 & 10 & 5 & 133 & 26 & 15 & 1.71 & 1.70 & 2.84 \\
\hline 7 & 9 & 9 & 7 & 126 & 21 & 13 & 1.87 & 1.70 & 2.46 \\
\hline 8 & 9 & 9 & 8 & 137 & 30 & 16 & 1.77 & 1.17 & 2.18 \\
\hline 9 & 10 & 8 & 8 & 118 & 20 & 14 & 1.20 & 0.96 & 2.30 \\
\hline 10 & 9 & 9 & 6 & 117 & 18 & 13 & 1.64 & 1.40 & 2.40 \\
\hline Mean & 9.7 & 9 & 6.9 & 129 & 29 & 17 & 1.65 & 1.39 & 2.42 \\
\hline SEM & 0.8 & 0.8 & 0.7 & 7 & 8 & 3 & 0.23 & 0.31 & 0.25 \\
\hline
\end{tabular}

Results are given as mean \pm standard error (SEM).

7 years, and the average number of tests per patient was $9 \pm 1$. The mean age of the first measurement of ventilatory parameters and maximal inspiratory pressure was $9 \pm 1$ years and $16.0 \pm 1.4$ years for the last test. Children stopped walking at an average age of $9.7 \pm 1$ years old. The mean values of IQ, V.IQ and P.IQ were $66 \pm 12,71 \pm 10$ and $79 \pm 17$, respectively.

\section{Changes in Respiratory Function With Age}

The timing of our measurements was not uniformly spaced and the patients were not all referred at the same age. Consequently, to study the average changes of all these parameters with age, we carried out a longitudinal analysis of the variations in lung function against time for each individual by linear regression analysis. From these individual slopes, we then calculated the mean values \pm SEM for each parameter.

\section{Ventilatory Parameters}

The absolute values of vital capacity, total lung capacity and $\mathrm{FEV}_{1}$ showed an ascending phase that stopped at a

TABLE 3-Age When DMD Children Presented a Peak Value of Respiratory Parameters, Expressed in Liter or Expressed in \% of Predicted Value

\begin{tabular}{ll}
\hline & Age (year) \\
\hline Respiratory parameters expressed in liter & \\
Maximal vital capacity & $13.0 \pm 0.5$ \\
Maximal total lung capacity & $14.6 \pm 0.4$ \\
Maximal FEV1 & $13.0 \pm 0.7$ \\
Respiratory parameters expressed in \% of predicted value & $11.5 \pm 0.7$ \\
Maximal vital capacity & $11.0 \pm 0.9$ \\
Maximal total lung capacity & $11.5 \pm 0.8$ \\
\hline
\end{tabular}

Results are given as mean \pm standard error $(\mathrm{SEM}) . \mathrm{FEV}_{1}$, forced expired volume in $1 \mathrm{sec}$. different age for each subject. The mean values of vital capacity, total lung capacity and $\mathrm{FEV}_{1}$ reached a peak at $13.0 \pm 0.5$ years, $14.6 \pm 0.4$ years and $13.0 \pm 0.7$ years, respectively. However, when we expressed these parameters as percentages of the predicted value, peak values were attained earlier, at $11.5 \pm 0.7$ years, $11.0 \pm 0.9$ years, and $11.6 \pm 0.8$ years (Table 3). After the peak, the ventilatory parameters started to decline with age (Fig. 1) and showed a mean decrease of $10.7 \pm 6.0 \%$ per year (vital capacity), $9.2 \pm 6.0 \%$ per year (total lung capacity) and $10.4 \pm 6.0 \%$ per year $\left(\mathrm{FEV}_{1}\right)$. Thus, after the peak, at around 12 years of age, the mean values of vital capacity, total lung capacity and $\mathrm{FEV}_{1}$ were, respectively, $85.2 \pm 6.6,101.2 \pm 5.5$, and $78.2 \pm 7.4 \%$ predicted. There was then a rapid decline to reach mean values of $53.3 \pm 4.4,74.2 \pm 4.1$, and $49.5 \pm 5.1 \%$ predicted by 15 years of age.

\section{Inspiratory Muscle Strength (Pimax)}

We could not determine the age at which the maximal inspiratory pressure peaked because after the first measurement and, differently from what was observed for the ventilatory parameters, the absolute values of maximal inspiratory pressure did not increase, but rather decreased, in eight children (Fig. 2). However, the absolute value of maximal inspiratory pressure declined only slightly with age and the mean rate for its decrease was $3.4 \pm 0.5 \mathrm{cmH}_{2} \mathrm{O}$ per year. When we expressed the maximal inspiratory pressure as $\%$ predicted, the mean rate of decrease amounted to $6.9 \pm 1.3 \%$ per year. This rate of decrease was significantly lower than what was observed for vital capacity and $\mathrm{FEV}_{1}(P<0.01)$. Thus, while at 12 years of age the mean maximal inspiratory pressure was $67.5 \pm 2.6 \%$ predicted, it decreased to $48.3 \pm 3.6 \%$ predicted by the age of 15 . 

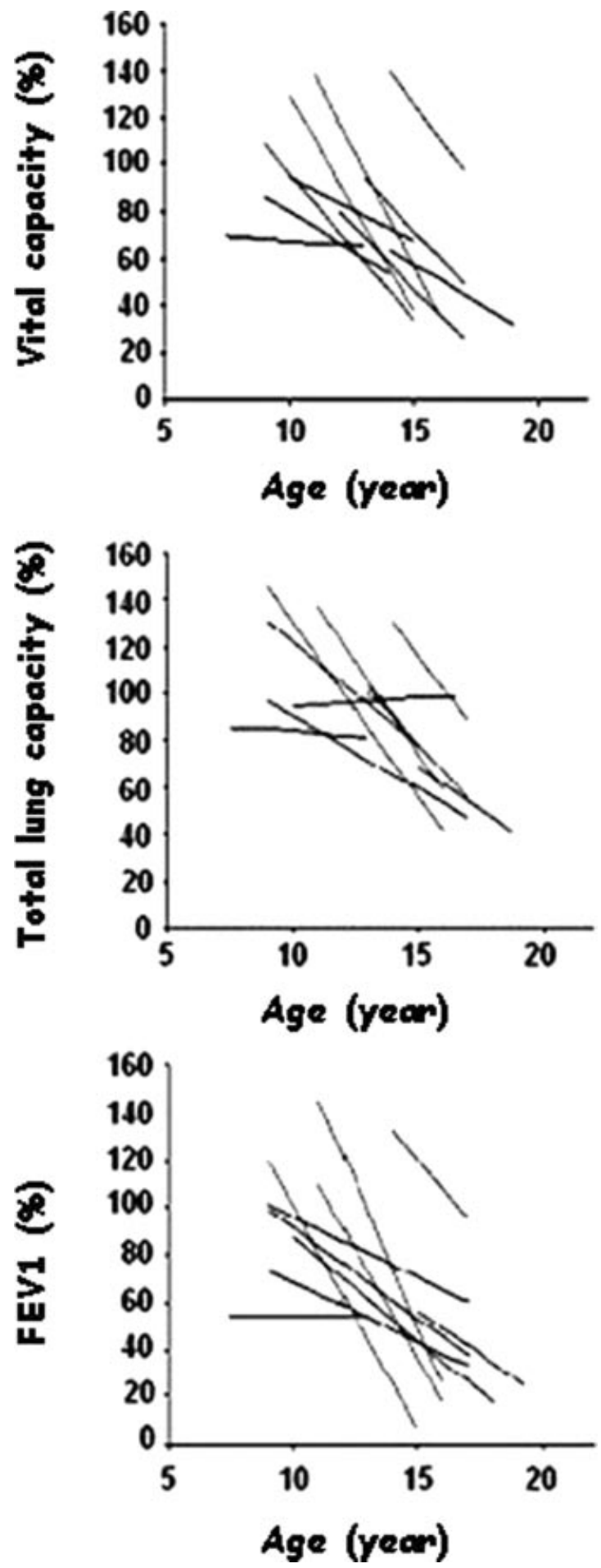

Fig. 1. Vital capacity vital, total lung capacity and forced expiratory volume in $1 \mathrm{sec}$ expressed as $\%$ of the predicted value in relation to age (years). Each line represents, for each patient, the significant linear relationship between a given ventilatory parameter and age, starting from the peak value until the last measurement.
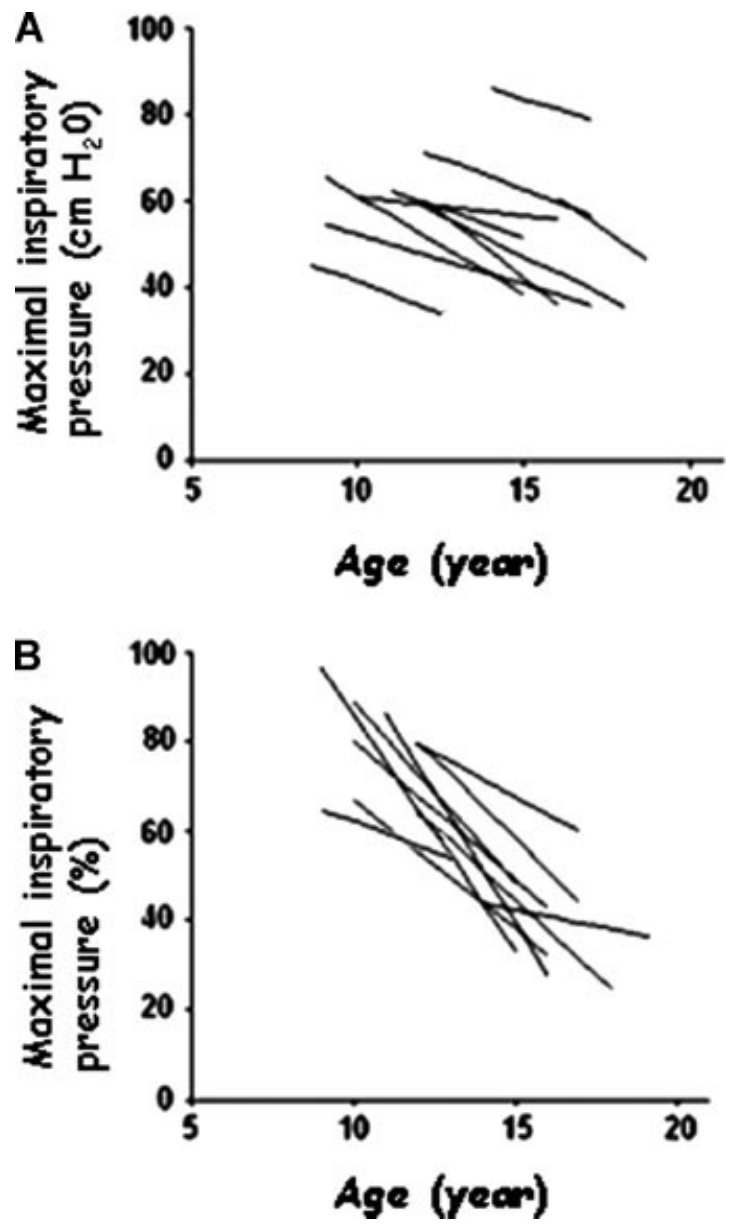

Fig. 2. Maximal inspiratory pressure (Pimax), expressed in absolute values $\left(\mathrm{cmH}_{2} \mathrm{O}\right)(\mathrm{A})$ and as $\%$ of the predicted value (B) in relation to age (years). Each line represents the significant linear relationship in a given patient between maximal inspiratory pressure and age starting from the peak or the initial values until the last measure.

\section{Correlation Between Ventilatory Parameters and Maximal Inspiratory Pressure}

We found a significant positive linear relationship $(P<0.05)$ between the individual rates of decrease of vital capacity or $\mathrm{FEV}_{1}$ and those of maximal inspiratory pressure [Vital capacity slope $(\%)=1.02 \times$ maximal inspiratory pressure slope $(\%)+4.48 ; \mathrm{FEV}_{1}$ slope $(\%)=1.21 \times$ maximal inspiratory pressure slope $(\%)+$ 3.69] (Fig. 3).

We then looked for possible relationships between individual values (expressed as \% predicted) of maximal inspiratory pressure and respectively, vital capacity, total lung capacity and $\mathrm{FEV}_{1}$ during the 7 years of follow-up (Fig. 4). The mean slopes and intercepts between vital capacity and Pimax were respectively $1.25 \pm 0.15$ and $4.1 \pm 0.15 \%$, whereas the corresponding values between $\mathrm{FEV}_{1}$ and Pimax were $1.3 \pm 0.5$ and $-5.39 \pm 0.43 \%$, and 

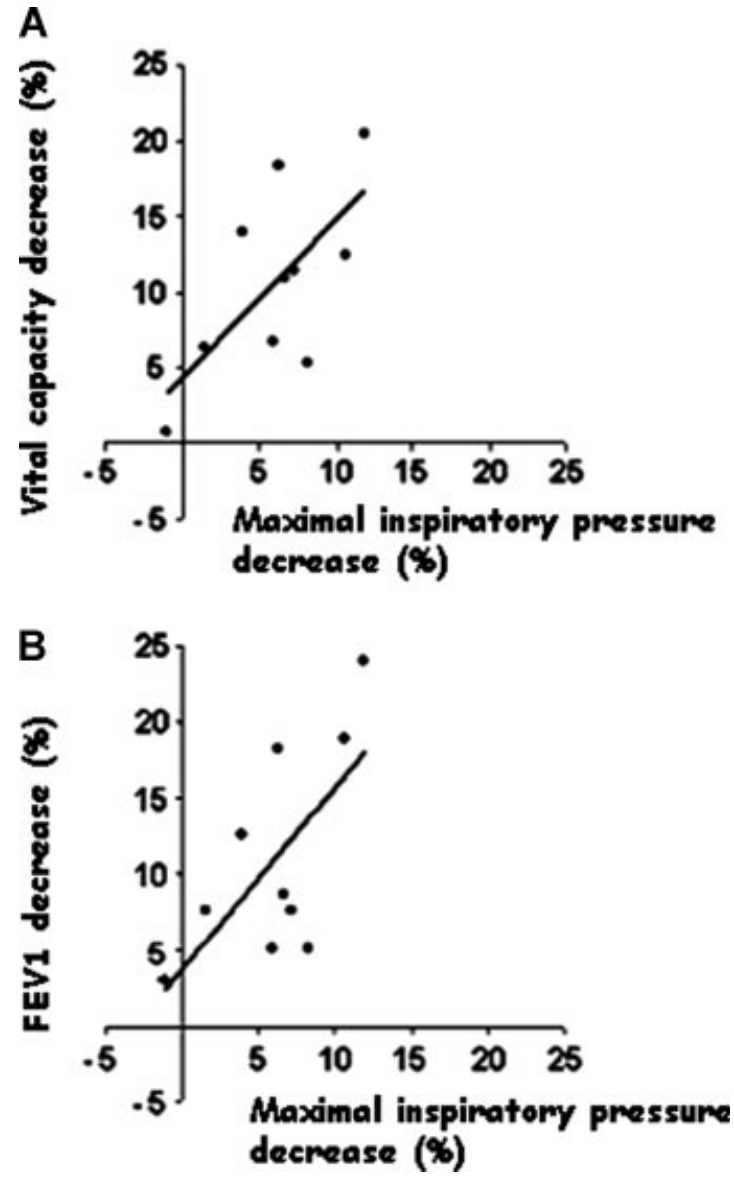

Fig. 3. Relationship between each patient's rate of decrease per year of vital capacity (A) or $\mathrm{FEV}_{1}(\mathrm{~B})$, and that of maximal inspiratory pressure. (VC slope $=1.02 \times$ maximal inspiratory pressure slope $+4.48 ; P<0.05, r=0.66$ and $\mathrm{FEV}_{1}$ slope $=$ $1.21 \times$ maximal inspiratory pressure slope +3.69 ). All parameters are expressed as \% of the predicted value. Each patient is represented by a single dot.

between total lung capacity and Pimax were $0.92 \pm 0.26$ and $39.75 \pm 0.26 \%$. We thus could observe that, as disease progressed, the discordances between the values of vital capacity and $\mathrm{FEV}_{1}$ versus maximal inspiratory pressure decreased, whereas those between total lung capacity and maximal inspiratory pressure persisted.

\section{DISCUSSION}

In this article, we present the first longitudinal, comparative follow-up study of the change in ventilatory parameters and maximal inspiratory pressure in DMD children during growth. This study has some limitations that must be considered. We have used in this study vital capacity, $\mathrm{FEV}_{1}$, and maximal inspiratory pressure, which are all volitional and indirect methods for the assessment of respiratory muscle function. Furthermore, measurements of maximal inspiratory pressures are not easy to perform, particularly in young patients with DMD.

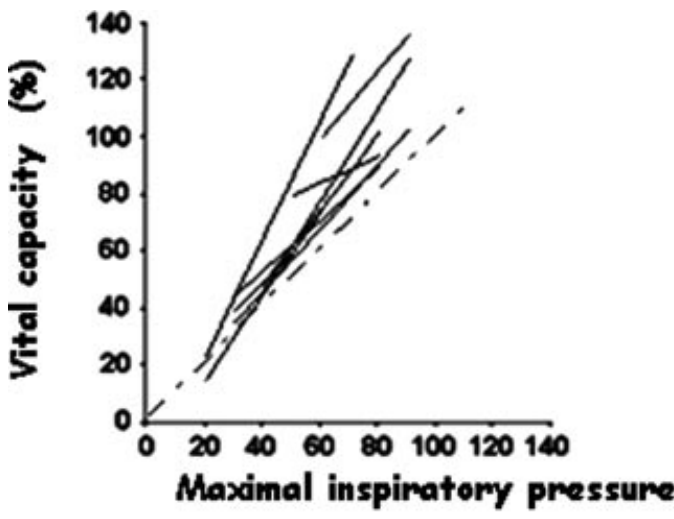

(\%)

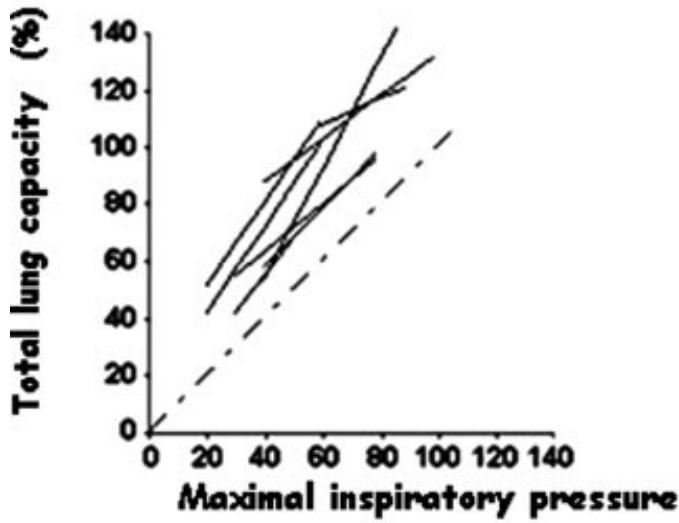

(\%)

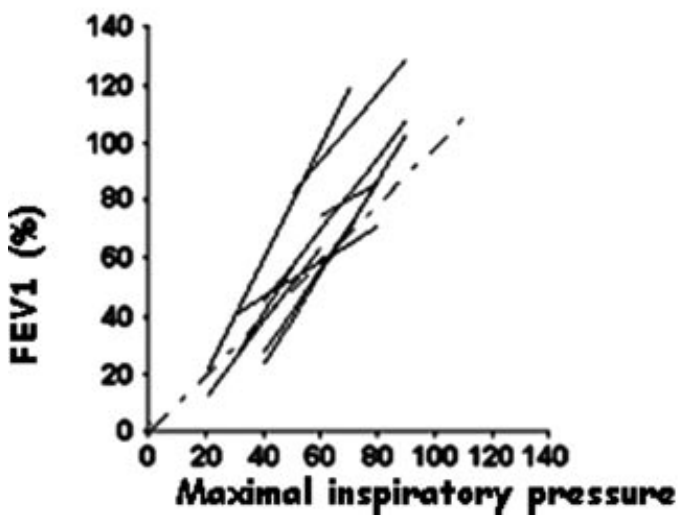

(\%)

Fig. 4. Vital capacity, total lung capacity, and forced expiratory volume in $1 \mathrm{sec}$ expressed as $\%$ of the predicted value in relation to maximal inspiratory pressure (Pimax) expressed as \% of the predicted value. Each line represents the significant linear relationship for a single patient between ventilatory parameters and maximal inspiratory pressure from the peak value until the last measure.

Alternative methods include sniff nasal inspiratory pressure (SNIP) ${ }^{21}$ or inspiratory flow reserve measurements. ${ }^{22}$ Interestingly, it has recently been reported that in DMD patients, Pimax may be more reliable than SNIP. ${ }^{21}$ While at the beginning of our study the use of SNIP was not generally accepted and we had a high level of experience with the use of Pimax, ${ }^{19,20,23,24}$ in the last period of our investigation we also performed SNIP measurements in some patients and obtained similar 
results to those reported for Pimax. Finally, the number of patients in our study was relatively low, and the measurement intervals were not uniform. Therefore, the patients were not all evaluated at the same age, since in the clinical follow-up setting it was difficult to impose the same pattern of evaluation in all DMD children.

As in previous cross-sectional studies, ${ }^{5,6,11}$ we found that vital capacity, total lung capacity and $\mathrm{FEV}_{1}$, when expressed in absolute values, showed a characteristic pattern with ascending, plateau, and then descending phases. We found, similarly to other authors, ${ }^{2,6,11}$ that the peak values of vital capacity, total lung capacity and $\mathrm{FEV}_{1}$ expressed as $\%$ of the predicted values occurred between 11 and 12 years of age, that is to say $2-3$ years earlier than the peak expressed in absolute terms. During this interval, although the ventilatory parameters still appeared to increase when expressed as absolute values, in reality they were already decreasing. Hence growth no longer compensates for the reduction in lung volume caused by the deterioration of muscular function. Therefore, we suggest that respiratory parameters should be expressed as $\%$ of predicted value since this better describes the relationships between growth compensation and respiratory function decline.

After reaching their peak values, vital capacity and total lung capacity decreased at a linear rate with age, leading to the appearance of a progressive restrictive ventilatory pattern. We found that the mean percentage decrease of vital capacity ( $10.7 \%$ per year) was slightly higher than that generally reported in previous studies. ${ }^{2,8,11}$ This difference could be due to the greater variability of the decline rate among our patients. We also observed that the reduction in $\mathrm{FEV}_{1}$ correlated with the decrease in lung volume, as previously shown by others, ${ }^{8,25}$ with a mean decrease of $10.4 \%$ per year.

Our results show that the recording of changes in maximal inspiratory pressure over time is useful to appreciate the loss of respiratory muscle strength in young DMD patients as well as for the sequential follow-up of their respiratory function. ${ }^{1,26,27}$ While the ventilatory parameters increased until the age of 13-14 years (when expressed in absolute values), maximal inspiratory pressure started to decline slightly from the age of 10 years onwards. This result could be explained by the fact that the maximum static pressure decreases early in the course of the disease, between 5 and 10 years of age. ${ }^{2,28}$ When we expressed maximal inspiratory pressure as $\%$ of predicted value, we found a decrease of maximal inspiratory pressure of $6.9 \%$ per year, which is slightly higher than that observed by Hahn et al. ${ }^{11}$ (5.9\% per year).

We then compared the changes in ventilatory parameters and maximal inspiratory pressure at different ages during disease progression. As observed by previous authors, at early stages of DMD, the vital capacity, total lung capacity and $\mathrm{FEV}_{1}$ were all within normal limits and significantly higher than maximal inspiratory pressure (all expressed as $\%$ of predicted value). The shape of the typical relaxed pressure-volume curve of the respiratory system may explain the preservation of the pulmonary volume despite the decreased inspiratory muscle strength. Indeed, the relationship between maximal inspiratory pressure and lung volume at an early stage of the disease is more hyperbolic than linear, with small variations of lung volume for a large decrease of maximal inspiratory pressure.

As the disease progressed, we found a positive correlation between the individual rates of decrease of vital capacity and $\mathrm{FEV}_{1}$ and those of maximal inspiratory pressure. This result mainly reflects the impact of diaphragmatic dysfunction on the ventilatory parameters. However, the decrease of maximal inspiratory pressure was slower than that of vital capacity and $\mathrm{FEV}_{1}$. This result is in accordance with previous studies reported by De Troyer et al. ${ }^{29}$ and Estenne et al. ${ }^{30}$ These authors showed that other factors (e.g., alterations of the elastic properties of elastin and collagen fibers, decreases in surfactant activity, ${ }^{31}$ ankylosis of the costosternal joints, scoliosis, fibrosis of the rib cage muscles, microatelectasis ${ }^{28}$ ) could contribute to the decrease of ventilatory parameters by causing a reduction in respiratory system compliance. .Thus, as the disease progresses, vital capacity and $\mathrm{FEV}_{1}$ are likely to be better indicators of global respiratory system involvement than maximal inspiratory pressure. Moreover, $\mathrm{FEV}_{1}$ (as \% of the predicted value) seems to be the ventilatory parameter that best reflects muscular dysfunction as it showed the highest correlation with maximal inspiratory pressure. This result is in accordance with previous studies which reported a correlation between $\mathrm{FEV}_{1}$ and maximal expiratory effort ${ }^{32}$ or between $\mathrm{FEV}_{1}$ and the muscular function score of the upper limbs. ${ }^{8}$ Conversely, the differences between total lung capacity and maximal inspiratory pressure persisted over time (Fig. 4), indicating that total lung capacity is a poor indicator of disease progression. This result is in agreement with those by Rideau et al. ${ }^{6}$ and Inkley et al. ${ }^{4}$ who found that while vital capacity decreases, residual volume increases due to inability of expiratory muscles to maximally empty the lungs.

At the age of 15 years on average, vital capacity, $\mathrm{FEV}_{1}$, and maximal inspiratory pressure (expressed as \% of predicted value) were comparable and, therefore, provided the same information about the functional impact of the disease on the respiratory system. This result could be useful for the clinicians who need to follow-up the respiratory function in DMD patients at later stages of the disease. Indeed, at advanced stages, vital capacity or $\mathrm{FEV}_{1}$ are often easier to measure than maximal inspiratory pressure, particularly since cognitive impairment is often present at that point. ${ }^{14}$ 
In conclusion, this longitudinal study, which follows the changes in ventilatory parameters and maximal inspiratory pressure in a group of DMD patients, shows that when ventilatory parameters expressed as percentages of their predicted values start to decrease, the slopes of the declines in vital capacity and $\mathrm{FEV}_{1}$ are better indicators of respiratory system disease progression than maximal inspiratory pressure. However, as Pimax is the more specific index of inspiratory muscle performance and affected earlier, both forms of assessment are complementary and may be useful for separating changes caused by inspiratory muscle weakness versus other phenomena.

\section{REFERENCES}

1. Hoffman EP, Brown RH, Jr., Kunkel LM. Dystrophin: the protein product of the Duchenne muscular dystrophy locus. Cell 1987; 51:919-928.

2. McDonald CM, Abresch RT, Carter GT, Fowler WM, Jr., Johnson ER, Kilmer DD, Sigford BJ. Profiles of neuromuscular diseases. Duchenne muscular dystrophy. Am J Phys Med Rehabil 1995; 74:S70-S92.

3. Nagai T. Prognostic evaluation of congestive heart failure in patients with Duchenne muscular dystrophy-retrospective study using non-invasive cardiac function tests. Jpn Circ J 1989;53: 406-415.

4. Inkley SR, Oldenburg FC, Vignos PJ, Jr. Pulmonary function in Duchenne muscular dystrophy related to stage of disease. Am J Med 1974;56:297-306.

5. Rideau Y. Prognosis of progressive muscular dystrophy in children. Analysis of early and exact criteria. Union Med Can 1977;106:874-882.

6. Rideau Y, Jankowski LW, Grellet J. Respiratory function in the muscular dystrophies. Muscle Nerve 1981;4:155-164.

7. Hukins CA, Hillman DR. Daytime predictors of sleep hypoventilation in Duchenne muscular dystrophy. Am J Respir Crit Care Med 2000;161:166-170.

8. Tangsrud S, Petersen IL, Lodrup Carlsen KC, Carlsen KH. Lung function in children with Duchenne's muscular dystrophy. Respir Med 2001;95:898-903.

9. Phillips MF, Quinlivan RC, Edwards RH, Calverley PM. Changes in spirometry over time as a prognostic marker in patients with Duchenne muscular dystrophy. Am J Respir Crit Care Med 2001; 164:2191-2194.

10. Black LF, Hyatt RE. Maximal respiratory pressures: normal values and relationship to age and sex. Am Rev Respir Dis 1969; 99:696-702.

11. Hahn A, Bach JR, Delaubier A, Renardel-Irani A, Guillou C, Rideau Y. Clinical implications of maximal respiratory pressure determinations for individuals with Duchenne muscular dystrophy. Arch Phys Med Rehabil 1997;78:1-6.

12. Baydur A. Respiratory muscle strength and control of ventilation in patients with neuromuscular disease. Chest 1991;99:330-338.

13. Braun NM, Arora NS, Rochester DF. Respiratory muscle and pulmonary function in polymyositis and other proximal myopathies. Thorax 1983;38:616-623.

14. Hinton GG. Childhood psychosis or mental retardation: a diagnostic dilemma. II. Pediatric and neurological aspects. Can Med Assoc J 1963;88:1020-1024.
15. ATS/ERS Respiratory mechanics in infants: physiologic evaluation in health and disease. Am Rev Respir Dis 1993;147:474-496.

16. Daftary AS, Crisanti M, Kalra M, Wong B, Amin R. Effect of long-term steroids on cough efficiency and respiratory muscle strength in patients with Duchenne muscular dystrophy. Pediatrics 2007;119:e320-e324.

17. Berard C, Payan C, Hodgkinson I, Fermanian J. A motor function measure for neuromuscular diseases. Construction and validation study. Neuromuscul Disord 2005;15:463-470.

18. Zapletal A, Paul T, Samanek M. Normal values of static pulmonary volumes and ventilation in children and adolescents. Cesk Pediatr 1976;31:532-539.

19. Matecki S, Prioux J, Amsallem F, Denjean A, Ramonatxo M. Maximal respiratory pressures in children: the methodological challenge. Rev Mal Respir 2004;21:1116-1123.

20. Matecki S, Prioux J, Jaber S, Hayot M, Prefaut C, Ramonatxo M. Respiratory pressures in boys from 11-17 years old: a semilongitudinal study. Pediatr Pulmonol 2003;35:368374.

21. Terzi N, Orlikowski D, Fermanian C, Lejaille M, Falaize L, Louis A, Raphael JC, Fauroux B, Lofaso F. Measuring inspiratory muscle strength in neuromuscular disease: one test or two? Eur Respir J 2008;31:93-98.

22. De Bruin PF, Ueki J, Bush A, A YM, Watson A, Pride NB. Inspiratory flow reserve in boys with Duchenne muscular dystrophy. Pediatr Pulmonol 2001;31:451-457.

23. Matecki S, Topin N, Hayot M, Rivier F, Echenne B, Prefaut C, Ramonatxo M. A standardized method for the evaluation of respiratory muscle endurance in patients with Duchenne muscular dystrophy. Neuromuscul Disord 2001;11:171-177.

24. Koechlin C, Matecki S, Jaber S, Soulier N, Prefaut C, Ramonatxo $\mathrm{M}$. Changes in respiratory muscle endurance during puberty. Pediatr Pulmonol 2005;40:197-204.

25. Gozal D. Pulmonary manifestations of neuromuscular disease with special reference to Duchenne muscular dystrophy and spinal muscular atrophy. Pediatr Pulmonol 2000;29:141150 .

26. Griggs RC, Donohoe KM, Utell MJ, Goldblatt D, Moxley RT III. Evaluation of pulmonary function in neuromuscular disease. Arch Neurol 1981;38:9-12.

27. Nicot F, Hart N, Forin V, Boule M, Clement A, Polkey MI, Lofaso F, Fauroux B. Respiratory muscle testing: a valuable tool for children with neuromuscular disorders. Am J Respir Crit Care Med 2006;174:67-74.

28. Smith PE, Calverley PM, Edwards RH, Evans GA, Campbell EJ. Practical problems in the respiratory care of patients with muscular dystrophy. N Engl J Med 1987;316:11971205 .

29. De Troyer A, Kelly S, Macklem PT, Zin WA. Mechanics of intercostal space and actions of external and internal intercostal muscles. J Clin Invest 1985;75:850-857.

30. Estenne M, Gevenois PA, Kinnear W, Soudon P, Heilporn A, De Troyer A. Lung volume restriction in patients with chronic respiratory muscle weakness: the role of microatelectasis. Thorax 1993;48:698-701.

31. Lynn DJ, Woda RP, Mendell JR. Respiratory dysfunction in muscular dystrophy and other myopathies. Clin Chest Med 1994; 15:661-674.

32. Krowka MJ, Enright PL, Rodarte JR, Hyatt RE. Effect of effort on measurement of forced expiratory volume in one second. Am Rev Respir Dis 1987;136:829-833. 